\title{
MANEJO TÉRMICO DO AR NA SECAGEM ESTACIONÁRIA E SEUS EFEITOS NO DESEMPENHO INDUSTRIAL DE ARROZ BRANCO E PARBOILIZADO
}

\author{
FABRIZIO DA FONSECA BARBOSA* \\ MOACIR CARDOSO ELIAS** \\ CARLOS ALBERTO ALVES FAGUNDES*** \\ MAURÍCIO DE OLIVEIRA**** \\ FLÁVIO MANETTI PEREIRA***** \\ RAFAEL GOMES DIONELLO ${ }^{\star \star \star \star \star *}$
}

\begin{abstract}
O presente trabalho teve por objetivo estudar o uso de diferentes manejos térmicos do ar na secagem de grãos de arroz classe longo-fino, com umidade entre 17 e $22 \%$ b.u., utilizando-se secagem estacionária em silossecadores industriais. $\mathrm{O}$ arroz úmido passou por cinco tratamentos de secagem: 1) em sistema alternado de insuflação-sucção, com controle operacional automatizado de umidade relativa do ar em $75 \%$, utilizando-se ar ambiente ou aquecido mediante queima de gás liquefeito de petróleo (GLP); 2) em sistema de insuflação, com controle automatizado de temperatura em $20^{\circ} \mathrm{C}$, utilizando-se ar ambiente sem aquecimento ou ar aquecido por queima de GLP; 3) em sistema de insuflação, com ar ambiente e controle realizado pelo operador; 4) em sistema de insuflação, com controle automatizado de umidade relativa do ar em $75 \%$, utilizando-se ar ambiente ou ar aquecido por queima de GLP; 5) em sistema alternado insuflaçãosucção de ar ambiente, sem aquecimento, com controle automatizado de umidade relativa em $75 \%$. Após a secagem, os grãos foram beneficiados pelo processo convencional de arroz branco polido ou por parboilização, sendo a seguir realizadas análises de desempenho industrial. $O$ estudo demonstrou que o uso de insuflação de ar, aliado ao controle das condições psicrométricas do ar, resulta em menor tempo de secagem, proporcionando menores perdas na qualidade dos grãos quando comparado à insuflação e sucção alternadas e ao uso de ar ambiente sem aquecimento.
\end{abstract}

PALAVRAS-CHAVE: ARROZ; GÁS LIQUEFEITO DE PETRÓLEO; PARBOILIZAÇÃO; RENDIMENTO DE ENGENHO; SECAGEM; SILO-SECADOR.

* Engenheiro Agrônomo, Doutor em Engenharia Agrícola, Professor Adjunto, Departamento de Ciência dos Alimentos (DCA), Universidade Federal de Pelotas (UFPel), Pelotas, RS (e-mail: fabriziobarbosa@yahoo.com.br).

** Engenheiro Agrônomo, Doutor em Agronomia, Professor Titular, DCTA, UFPel, Pelotas, RS (e-mail: eliasmc@ufpel.tche.br).

*** Engengenheiro Agrônomo, Mestre em Ciência e Tecnologia Agroindustrial, Pesquisador, Instituto Rio Grandense do Arroz (IRGA), Cachoeirinha, RS (e-mail: irgaposcol@via-rs.net).

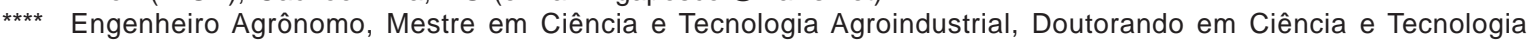
Agroindustrial, DCTA, UFPel, Pelotas, RS (e-mail: palmito.tche@pop.com.br).

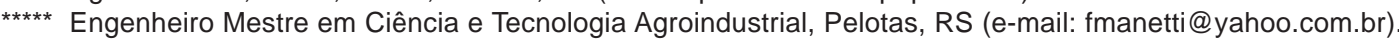

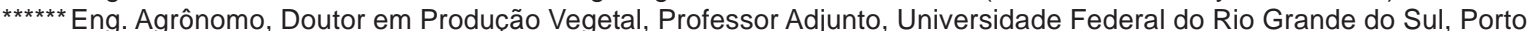
Alegre, RS (e-mail:rafdionello@hotmail.com). 


\section{INTRODUÇÃO}

O arroz, produto de importância mundial, é produzido em todos os continentes, sendo o asiático responsável por $90 \%$ da produção mundial. Na América Latina, o Brasil destaca-se como o maior produtor, alcançando na safra 2007/2008 mais de 12 milhões de toneladas (CONAB, 2009). Desse montante, o Rio Grande do Sul foi responsável por mais de $60 \%$, o que representa 2,23\% do PIB e cerca de $3 \%$ da arrecadação de ICMS do estado (IRGA, 2009). Além disso, essa cultura no Rio Grande do Sul envolve mais de 137 municípios e cerca de 15 mil famílias gerando 350 mil empregos diretos (SANTOS, 2006).

Dentre os cereais, o arroz constitui o principal alimento para a grande maioria da população da América Latina e do Caribe. A disponibilidade, o preço do produto e o poder aquisitivo da população têm feito com que o consumo médio de arroz no Brasil varie na faixa de 42 a $47 \mathrm{~kg}$. habitante ${ }^{-1}$. ano $^{-1}$, tomando-se por base o grão beneficiado (TAVARES, 2004).

A umidade adequada para a colheita não coincide com a do armazenamento e beneficiamento dos grãos, por isso torna-se indispensável o uso de secagem. A colheita realizada na faixa de umidade recomendada minimiza perdas, mas requer o uso de secagem artificial (ELIAS, 2004; SOSBAI, 2003; FAN, SIEBENMORGENT e YANG., 2000).

Os métodos de secagem podem ser divididos em naturais e artificiais. Em vista das limitações dos métodos naturais de secagem, que necessitam da ocorrência de combinações favoráveis de fatores sob os quais não se tem controle, os métodos mais comumente empregados são os artificiais. A secagem artificial ou forçada do arroz é amplamente utilizada em regiões que dispõem de alta tecnologia de produção. Nos métodos de secagem artificial são empregadas diversas condições de temperatura e fluxo de ar, tempo e formas de movimentação dos grãos e de contato entre o ar e os grãos, havendo muitos modelos de secadores comerciais conforme o princípio de operação (BARBOSA et al., 2002; ELIAS, 2002, LORINI, MIIKR e SCUSSEL, 2002).

A secagem estacionária, método artificial, caracteriza-se pela passagem forçada do ar, aquecido ou não, em fluxo axial ou radial através da camada de grãos que permanece parada no compartimento de secagem. Autilização de ar sem aquecimento depende das condições psicrométricas do ar ambiente e, além da morosidade e do baixo fluxo operacional, apresenta risco de desenvolvimento microbiano durante o processo. A secagem estacionária, realizada em silo-secador, está sendo utilizada com êxito por diversos produtores; entretanto ainda requer muitos estudos (ELIAS, 2004; CONRAD et al., 2003; BARBOSA et al., 2001).

Para o aquecimento do ar podem ser utilizados diversos tipos de combustíveis, sendo a lenha e a casca do arroz os mais utilizados. Esses combustíveis sólidos não garantem uniformidade na secagem pela grande oscilação de temperatura durante a operação, razão pela qual se busca combustíveis fluidos para diminuir o problema. A liberação por parte do governo do uso de combustíveis derivados do petróleo, como o gás liquefeito de petróleo (GLP) para o aquecimento do ar de secagem, abre a porta para o estudo desses combustíveis (ELIAS, FAGUNDES e DIAS, 2004; PEREIRA et al., 2003; BARBOSA et al., 2001).

Segundo ELIAS (1998), o beneficiamento do arroz pode ser realizado pelos processos convencional (branco polido) ou parboilização. O beneficiamento convencional, o mais aplicado no Brasil, representa cerca de $70 \%$ do arroz consumido (branco polido). Entretanto, esse percentual tende a diminuir, pois o consumo de arroz parboilizado vem aumentando gradativamente (ABIAP, 2009).

O beneficiamento por parboilização, processo que altera a forma do amido de cristalina para amorfa, difere do convencional pelos tratamentos hidrotérmicos antes do beneficiamento dos grãos. A hidratação ou encharcamento tem por objetivo umedecer o grão e a etapa de autoclavagem a finalidade de gelatinizar o amido. A secagem posterior promove a retrogradação do amido (AMATO, CARVALHO e SILVEIRAFILHO, 2002).

O beneficiamento do arroz por parboilização permite, em parte, atenuar alguns danos causados aos grãos durante a secagem como o trincamento e a desestruturação do amido, diminuindo o percentual 
de grãos quebrados. Também reduz as perdas do valor nutritivo e aumenta a digestibilidade, entretanto intensifica o aparecimento de defeitos gerais e graves (AMATO e ELIAS, 2005; AMATO, CARVALHO e SILVEIRA FILHO, 2002).

Objetivou-se com este trabalho estudar o uso do GLP (Gás Liquefeito de Petróleo) no condicionamento do ar e seus efeitos no desempenho industrial de grãos de arroz irrigado.

\section{MATERIAL E MÉTODOS}

\subsection{MATÉRIA-PRIMA}

Foram utilizados grãos de arroz em casca da classe longo-fino (agulhinha), produzidos no Rio Grande do Sul, colhidos com umidade entre 17 e $22 \%$ base úmida (b.u.), e submetidos à pré-limpeza em máquina industrial de ar e peneiras até que os teores de impurezas e/ou matérias estranhas fossem reduzidos a aproximadamente $2 \%$.

\subsection{CARACTERIZAÇÃO DA MATÉRIA-PRIMA}

Imediatamente após a pré-limpeza, amostras de cada silo-secador foram coletadas e secadas em secador de amostras (sistema estacionário, com temperatura do ar de $50 \pm 5^{\circ} \mathrm{C}$ ) para que fossem determinadas suas características iniciais de umidade e de desempenho industrial.

\subsection{SECAGEM}

Realizou-se a secagem na Estação Experimental do Arroz (EEA) do Instituto Rio Grandense do Arroz (IRGA), em Cachoeirinha-RS. Foram utilizados silos-secadores industriais com capacidade para 250 toneladas de grãos, com ar em fluxo axial, dotados de fundo falso (plenum) com chapa plana perfurada, ventiladores, sistema de automação para controle e monitoramento e queimadores de gás liquefeito de petróleo (GLP).

Os tratamentos realizados consistiram em cinco manejos operacionais do ar de secagem conforme segue:

Manejo 1 - Operação em sistema alternado insuflação-sucção do ar, com controle operacional automatizado. Na sucção sempre foi utilizado ar natural, sem aquecimento com umidade relativa (UR) igual ou inferior a $75 \%$. Na insuflação também foi utilizado ar com UR igual ou inferior a 75\%. Quando o ar apresentava UR acima de 75\% acionava-se automaticamente o queimador de GLP para condicionar o ar até a UR desejada (75\%) e caso a umidade estivesse igual ou inferior a 75\% utilizava-se o ar natural, sem aquecimento.

Manejo 2 - Operação em sistema de insuflação do ar, com controle operacional automatizado de temperatura. Nesse tratamento, quando a temperatura do ar estava em $20^{\circ} \mathrm{C}$ ou superior utilizava-se ar ambiente sem aquecimento. Quando a mesma encontrava-se abaixo de $20^{\circ} \mathrm{C}$ acionava-se automaticamente o queimador de GLP para elevar a temperatura até o valor desejado.

Manejo 3 - Operação em sistema de insuflação do ar, com controle realizado pelo operador. Nesse tratamento, foi utilizado somente ar ambiente sem aquecimento; e o operador, com base nas condições psicrométricas do ar (temperatura e umidade relativa) definia qual o melhor momento de acionar o sistema de ventilação.

Manejo 4 - Operação em sistema de insuflação do ar, com controle automatizado de umidade relativa. 
Quando o ar apresentava UR acima de 75\%, acionava-se automaticamente o queimador de GLP para condicionar o ar até a UR desejada (75\%) e, caso a umidade estivesse igual ou inferior a 75\%, utilizava-se o ar natural, sem aquecimento.

Manejo 5 - Operação em sistema alternado insuflação-sucção de ar ambiente, com controle automatizado de umidade relativa. Nesse tratamento, os ventiladores só foram acionados quando a UR do ar ambiente estava com valor igual ou inferior a 75\%, não havendo mecanismo de correção da UR. Esse processo foi realizado em ciclos, sendo que nos primeiros utilizou-se somente insuflação e nos seguintes sucção até o final do processo de secagem.

Para se determinar o final da secagem, efetuava-se o controle diário da umidade dos grãos, mediante coleta de amostras com auxílio de calador pneumático em diferentes alturas a partir da base do silo-secador (40, 120 e 200 cm) e na superfície da camada de grãos.

\subsection{DETERMINAÇÃO DE UMIDADE}

As análises de umidade das amostras foram realizadas, em três repetições, de 10 gramas cada pelo método oficial, em estufa com circulação natural de ar em temperatura de $105 \pm 3^{\circ} \mathrm{C}$ por 24 horas, conforme as Regras para Análise de Sementes (BRASIL, 1992).

\subsection{DESEMPENHO INDUSTRIAL}

O desempenho industrial foi avaliado no Laboratório de Pós-Colheita e Industrialização de Grãos, Departamento de Ciência e Tecnologia Agroindustrial (DCTA) da Universidade Federal de Pelotas em Capão do Leão (RS).

As análises foram realizadas antes e logo após a secagem para caracterização inicial da matériaprima. Amostras de grãos de arroz, com umidade em torno de $13 \%$ de umidade (b.u.) foram submetidas ao beneficiamento pelos processos convencional (branco polido) e por parboilização, utilizando-se engenho de provas Suzuki ${ }^{\circledR}$, em conformidade com a Portaria 269 do Ministério da Agricultura (BRASIL, 1988). As condições utilizadas no processo de parboilização foram determinadas por testes preliminares de acordo com a metodologia descrita por ELIAS (1998).

\subsection{ANÁLISE ESTATÍSTICA}

Utilizou-se delineamento experimental inteiramente casualizado. Os dados obtidos foram analisados estatisticamente pelo software SAEG ${ }^{\circledR}$, versão 9.1 (SAEG, 2009), sendo a significância estatística estudada mediante análise de variância (ANOVA) e teste de Duncan $(p<0,05)$.

\section{RESULTADOS E DISCUSSÃO}

\subsection{SECAGEM}

Na Tabela 1, estão apresentados os resultados referentes aos teores de água (iniciais e finais) e tempos de secagem.

De acordo com os resultados apresentados na Tabela 1, pode-se observar que somente o uso de insuflação na secagem com controle automatizado de temperatura (Manejo 2) ou de umidade relativa (Manejo 4) proporciona os menores tempos de secagem em relação à insuflação de ar natural sem aquecimento e com controle realizado pelo operador (Manejo 3) ou de insuflação e sucção alternados (Manejos 1 e 5). 


\section{TABELA 1 - UMIDADE (INICIAL E FINAL) E TEMPO DE SECAGEM DE GRÃOS DE ARROZ, CLASSE LONGO-FINO, SUBMETIDOS A CINCO MANEJOS DE AR NA SECAGEM ESTACIONÁRIA EM SILO-SECADOR}

\begin{tabular}{lcrc}
\hline $\begin{array}{l}\text { Manejo do ar de } \\
\text { secagem }\end{array}$ & $\begin{array}{c}\text { Umidade inicial } \\
(\% \text { b.u. })\end{array}$ & $\begin{array}{c}\text { Umidade final } \\
(\% \text { b.u. })\end{array}$ & $\begin{array}{c}\text { Tempo de } \\
\text { secagem (dias) }\end{array}$ \\
\hline Manejo 1 & 20,27 & 13,55 & 57 \\
Manejo 2 & 18,78 & 13,18 & 32 \\
Manejo 3 & 19,21 & 13,73 & 71 \\
Manejo 4 & 18,35 & 13,17 & 35 \\
Manejo 5 & 19,38 & 13,93 & 78 \\
\hline
\end{tabular}

Comparando os tratamentos em que foi utilizado ar natural, sem aquecimento (Manejos 3 e 5 ) com os tratamentos em que houve controle das condições psicrométricas do ar (Manejos 1, 2 e 4), o tempo de secagem foi maior.

Nos tratamentos com insuflação e sucção alternadamente (Manejos 1 e 5), o tempo de secagem foi maior quando se utilizou ar natural sem aquecimento (Manejo 5).

A demora no processo de secagem pode causar desenvolvimento microbiano e posteriormente aumento na incidência de defeitos de origem metabólica nos grãos, ocasionando diminuição na sua qualidade.

\subsection{BENEFICIAMENTO INDUSTRIAL}

Na Tabela 2 são apresentados os resultados obtidos para o rendimento de grãos inteiros submetidos a cinco manejos operacionais de secagem e beneficiados pelo processo convencional de produção de arroz branco polido e por parboilização.

TABELA 2 - RENDIMENTO DE GRÃOS INTEIROS (\%) DE ARROZ CLASSE LONGO-FINO SUBMETIDOS A CINCO MANEJOS DE AR NA SECAGEM ESTACIONÁRIA, EM SILO-SECADOR, E BENEFICIADOS PELO PROCESSO CONVENCIONAL BRANCO POLIDO E POR PARBOILIZAÇÃO ${ }^{1}$

\begin{tabular}{lcc}
\hline \multirow{2}{*}{ Manejo do ar de secagem } & \multicolumn{2}{c}{ Período de avaliação } \\
\cline { 2 - 3 } Manejo 1 - Branco polido & Antes da secagem & Logo após a secagem \\
Manejo 2 - Branco polido & B 62,44 a & B 62,36 a \\
Manejo 3 - Branco polido & B 62,59 a & B 62,53 a \\
Manejo 4 - Branco polido & A 63,52 a & A 63,57 a \\
Manejo 5 - Branco polido & B 62,34 a & B 62,42 a \\
\hline Manejo 1 - Parboilizado & B 62,56 a & B 62,61 a \\
Manejo 2 - Parboilizado & A 66,24 a & A 66,17 a \\
Manejo 3 - Parboilizado & A 66,25 a & A 66,23 a \\
Manejo 4 - Parboilizado & A 66,17 a & A 66,30 a \\
Manejo 5 - Parboilizado & A 66,28 a & A 66,21 a \\
\hline
\end{tabular}

${ }^{1}$ Letras minúsculas distintas na mesma linha e letras maiúsculas distintas na mesma coluna diferem significativamente entre si pelo teste de Duncan a 5\% de probabilidade. 
Observando os resultados da Tabela 2, é possível verificar que o processo de secagem não influenciou o rendimento de grãos inteiros. Já o processo de industrialização influenciou, tendo a parboilização proporcionado incremento nesse parâmetro quando comparado com o processo convencional branco polido. Esse incremento se deve à gelatinização do amido e à consequente recuperação de grãos quebrados e trincados, associado à reestruturação interna dos grãos, que aumenta sua resistência às ações de fricção e abrasão que ocorrem no descascamento e no polimento (ELIAS et al., 2003; GUTKOSKI e ELIAS, 1992; GUTKOSKI, 1991). Além disso, durante o processo de parboilização há expansão dos grânulos de amido e da estrutura proteica do endosperma, preenchendo os espaços originalmente ocupados pelo ar, tornando o endosperma compacto e translúcido e aumentando seu grau de dureza (AMATO, CARVALHO e SILVEIRA FILHO, 2002; BATTACHARYA e ALI, 1985).

Na Tabelas 3 a 5 são apresentados os defeitos de origem metabólica, os de origem não metabólica e os defeitos totais.

\section{TABELA 3 - DEFEITOS DE ORIGEM METABÓLICA (\%) DE GRÃOS DE ARROZ CLASSE LONGO-FINO SUBMETIDOS A CINCO MANEJOS DE AR NA SECAGEM ESTACIONÁRIA, EM SILO-SECADOR E BENEFICIADOS PELO PROCESSO CONVENCIONAL BRANCO POLIDO E POR PARBOILIZAÇÃO ${ }^{1}$}

\begin{tabular}{lcc}
\hline \multirow{2}{*}{ Manejo do ar de secagem } & \multicolumn{2}{c}{ Período de avaliação } \\
\cline { 2 - 3 } & Antes da secagem & Logo após a secagem \\
\hline Manejo 1 - Branco polido & A 1,21 b & B 2,19 a \\
Manejo 2 - Branco polido & B 1,03 b & C 1,34 a \\
Manejo 3 - Branco polido & A 1,24 b & A 2,97 a \\
Manejo 4- Branco polido & B 0,92 b & C 1,33 a \\
Manejo 5 - Branco polido & B 1,04 b & B 2,36 a \\
\hline Manejo 1 - Parboilizado & A 1,84 b & A 3,60 a \\
Manejo 2 - Parboilizado & B 1,33 b & B 1,91 a \\
Manejo 3 - Parboilizado & A 1,69 b & A 3,60 a \\
Manejo 4- Parboilizado & B 1,35 b & B 2,11 a \\
Manejo 5- Parboilizado & B 1,34 b & A 4,02 a \\
\hline
\end{tabular}

${ }^{1}$ Letras minúsculas distintas na mesma linha e letras maiúsculas distintas na mesma coluna diferem significativamente entre si pelo teste de Duncan a 5\% de probabilidade.

Conforme os resultados constantes da Tabela 3, os defeitos de origem metabólica (grãos picados, manchados, amarelos, ardidos e pretos) se intensificaram durante a secagem. Esse aumento mostrou-se mais acentuado nos tratamentos em que foi utilizado ar natural, sem aquecimento. A lentidão da operação, aliada ao longo período de elevada umidade dos grãos permite que a ação enzimática ative o metabolismo dos próprios grãos e dos organismos associados ainda durante a secagem. A temperatura durante o dia, na maior parte do tempo em que ocorreu a secagem, situava-se entre 20 e $30^{\circ} \mathrm{C}$, havendo redução apenas durante a noite. Esses fatores 
associados resultaram no aparecimento de defeitos de origem metabólica e/ou em sua intensificação. Também se observa que o processamento por parboilização aumenta o rendimento de grãos inteiros, mas intensifica a incidência de defeitos resultantes de ações metabólicas.

\section{TABELA 4 - DEFEITOS DE ORIGEM NÃO METABÓLICA (\%) EM ARROZ CLASSE LONGO-FINO SUBMETIDO A CINCO MANEJOS DE AR NA SECAGEM ESTACIONÁRIA, EM SILO-SECADOR, E BENEFICIADOS PELO PROCESSO CONVENCIONAL BRANCO POLIDO E POR PARBOILIZAÇÃO ${ }^{1}$}

\section{Manejo do ar de secagem}

Período de avaliação

Antes da secagem

Logo após a secagem

\begin{tabular}{lll}
\hline Manejo 1 - Branco polido & A 0,93 a & A 0,91 a \\
Manejo 2 - Branco polido & B 0,23 a & B 0,24 a \\
Manejo 3 - Branco polido & B 0,34 a & B 0,32 a \\
Manejo 4 - Branco polido & B 0,35 a & B 0,36 a \\
Manejo 5 - Branco polido & B 0,24 a & B 0,23 a \\
\hline Manejo 1 - Parboilizado & A 0,94 a & A 0,97 a \\
Manejo 2 - Parboilizado & A 1,01 a & A 0,91 a \\
Manejo 3 - Parboilizado & A 1,13 a & A 1,08 a \\
Manejo 4 - Parboilizado & A 1,02 a & A 0,97 a \\
Manejo 5 - Parboilizado & A 1,02 a & A 1,05 a \\
\hline
\end{tabular}

${ }^{1}$ Letras minúsculas distintas na mesma linha e letras maiúsculas distintas na mesma coluna diferem significativamente entre si pelo teste de Duncan a 5\% de probabilidade.

Os resultados constantes da Tabela 4 evidenciam que o processo de beneficiamento industrial influenciou os defeitos de origem metabólica, havendo maior incidência nos grãos parboilizados. Isso se explica porque no processo de parboilização, embora haja a recuperação de grãos gessados e trincados, ocorre aumento de grãos danificados.

O aumento na incidência de defeitos de origem não metabólica (Tabela 4) proporcionado pela parboilização foi menos intenso quando comparado com os de origem metabólica (Tabela 3), independentemente do tratamento de secagem utilizado.

Conforme a Tabela 5 verifica-se que o comportamento do total de defeitos foi semelhante aos de natureza metabólica (Tabela 3) representando maior efeito proporcional no aumento do total de defeitos. Tanto os defeitos de origem metabólica, como os totais de defeitos foram intensificados nos tratamentos em que no manejo térmico do ar foi utilizado somente ar ambiente, sem condicionamento para aumento de temperatura ou redução de umidade relativa, o que acelerava o processo. A atividade metabólica dos grãos e dos organismos associados devido à lentidão da operação de secagem e o tempo decorrido até a redução da umidade para valores adequados à conservação explicam os comportamentos observados. 


\section{TABELA 5 - TOTAL DE DEFEITOS (\%) EM GRÃOS DE ARROZ, CLASSE LONGO-FINO, SUBMETIDOS A CINCO MANEJOS DE AR NA SECAGEM ESTACIONÁRIA, EM SILO-SECADOR, E BENEFICIADOS PELO PROCESSO CONVENCIONAL BRANCO POLIDO E POR PARBOILIZAÇÃO ${ }^{1}$}

\begin{tabular}{|c|c|c|}
\hline \multirow{2}{*}{ Manejo do ar de secagem } & \multicolumn{2}{|c|}{ Período de avaliação } \\
\hline & Antes da secagem & Logo após a secagem \\
\hline Manejo 1 - Branco polido & A $2,14 \mathrm{~b}$ & A 3,10 a \\
\hline Manejo 2 - Branco polido & C $1,26 \mathrm{~b}$ & C $1,58 \mathrm{a}$ \\
\hline Manejo 3 - Branco polido & B $1,58 \mathrm{~b}$ & A 3,29 a \\
\hline Manejo 4-Branco polido & C $1,27 \mathrm{~b}$ & C $1,69 \mathrm{a}$ \\
\hline Manejo 5 - Branco polido & C $1,28 \mathrm{~b}$ & B 2,59 a \\
\hline Manejo 1 - Parboilizado & A $2,78 \mathrm{~b}$ & A 4,57 a \\
\hline Manejo 2 - Parboilizado & B $2,34 \mathrm{~b}$ & B 2,82 a \\
\hline Manejo 3 - Parboilizado & A 2,82 b & A 4,68 a \\
\hline Manejo 4 - Parboilizado & B $2,37 \mathrm{a}$ & B 3,08 a \\
\hline Manejo 5 - Parboilizado & B $2,36 \mathrm{a}$ & A 5,07 a \\
\hline
\end{tabular}

${ }^{1}$ Letras minúsculas distintas na mesma linha e letras maiúsculas distintas na mesma coluna diferem significativamente entre si pelo teste de Duncan a $5 \%$ de probabilidade.

Na Tabela 6 são apresentados os resultados para o rendimento de grãos inteiros sem defeitos.

TABELA 6 - RENDIMENTO DE GRÃOS INTEIROS SEM DEFEITOS (\%) DE ARROZ CLASSE LONGO-FINO, SUBMETIDOS A CINCO MANEJOS DE AR NA SECAGEM ESTACIONÁRIA, EM SILO-SECADOR, E BENEFICIADOS PELO PROCESSO CONVENCIONAL BRANCO POLIDO E POR PARBOILIZAÇÃO ${ }^{1}$

\begin{tabular}{lcc}
\hline \multirow{2}{*}{ Manejo do ar de secagem } & \multicolumn{2}{c}{ Período de avaliação } \\
\cline { 2 - 3 } Manejo 1 - Branco polido & Antes da secagem & Logo após a secagem \\
Manejo 2 - Branco polido & C 60,30 a & D 59,26 b \\
Manejo 3 - Branco polido & B 61,33 a & A 60,95 a \\
Manejo 4 - Branco polido & A 61,93 a & BC 60,28 b \\
Manejo 5 - Branco polido & B 61,08 a & AB 60,73 a \\
\hline Manejo 1 - Parboilizado & B 61,29 a & C 60,02 b \\
Manejo 2 - Parboilizado & A 63,46 a & B 61,60 b \\
Manejo 3 - Parboilizado & A 63,92 a & A 63,41 a \\
Manejo 4 - Parboilizado & A 63,34 a & B 61,61 b \\
Manejo 5 - Parboilizado & A 63,91 a & A 63,13 a \\
\hline
\end{tabular}

${ }^{1}$ Letras minúsculas distintas na mesma linha e letras maiúsculas distintas na mesma coluna diferem significativamente entre si pelo teste de Duncan a $5 \%$ de probabilidade. 
Os resultados apresentados na Tabela 6 mostram variações na qualidade dos grãos durante 0 processo de secagem, sendo os prejuízos maiores nos manejos com maior lentidão na secagem. Esses resultados demonstram correlação entre os danos causados aos grãos e a lentidão na secagem. Quanto menor for o percentual de grãos inteiros sem defeitos, menor será o rendimento em arroz do tipo 1 , que apresenta maior valor no comércio e interessa tanto aos agricultores quanto à agroindústria.

Os defeitos de origem metabólica decorrem de danos latentes que se manifestam durante o armazenamento e tendem à intensificação. $O$ aumento do tempo de armazenamento, não estudado por não ser objeto do presente trabalho, intensificaria a incidência de defeitos de origem metabólica e reduziria os teores de grãos inteiros sem defeitos nos tratamentos cuja secagem ocorre sem condicionamento de umidade relativa ou temperatura.

\section{CONCLUSÃO}

O uso de somente insuflação de ar, assim como o controle das condições psicrométricas do ar, resulta em menor tempo de secagem, proporcionando menores perdas na qualidade dos grãos, quando comparado com a insuflação e sucção alternadas e o uso de ar ambiente sem aquecimento.

\section{ABSTRACT \\ THERMAL HANDLING OF AIR ON STATIONARY DRYING AND ITS EFFECTS ON INDUSTRIAL PERFORMANCE OF WHITE AND PARBOILIZED RICE}

The present work aims at studying the use of different thermal handlings of air on the drying of long-fine type rice with humidity between 17 and 22\% w.b., using stationary drying, in industrial flat bottom drying silos. The humid Rice was submitted to five different processes: 1) in an alternated system of inflation-suction, with automatized control of air humidity in $75 \%$, using ambience without heating air or air heated through burning of liquified gas made from petroleum (LGP); 2) in a system of insuflation, with automatized control of temperature in $20^{\circ} \mathrm{C}$, using ambience air without heating or air heated by burning of LGP; 3 ) in an insuflation system, using ambience air without heating, with manual control of temperature and humidity; 4) in an insuflation system, with automatized control of air humidity in $75 \%$, using ambience air without heating or air heated by burning of LGP; 5) in an alternated insuflation-suction system of ambience air without heating, with automatized control of air humidity in $75 \%$. After the drying, the grains went through the standard process used to obtain white rice or suffered parboilization, and were later submitted to analysis of industrial performance. The study leads to conclude that the use of insuflation, along with the control of the psychometric conditions of air, results in less time of drying and, consequently, a better quality of the grains, if compared to the alternated insuflation and suction and to the use of unheated ambience air.

KEY-WORDS: RICE; LIQUEFIED GAS OF PETROLEUM; PARBOILING; INDUSTRIAL PERFORMANCE; DRYING; DRYING SILOS.

\section{REFERÊNCIAS}

1 ABIAP. Associação Brasileira das Indústrias de Arroz Parboilizado. Arroz branco ou parboilizado? Disponível em: <http://www.abiap.com.br>. Acesso em: 30 nov. 2009.

2 AMATO, G.W.; CARVALHO, J.L.V.; SILVEIRA FILHO, S. Arroz parboilizado: tecnologia limpa, produto nobre. Porto Alegre: Ricardo Lenz, 2002. 240 p.

3 AMATO, G. W.; ELIAS, M. C. A parboilização do arroz. Porto Alegre-RS: Ricardo Lenz, 2005. 160 p.

4 BARBOSA, F.F.; FAGUNDES, C.A.A.; MARTINS, I.R.; ELIAS, M.C. GLP para o aquecimento do ar na secagem estacionária do arroz irrigado. In: CONGRESSO BRASILEIRO DO ARROZ IRRIGADO, 2., REUNIÃO DA CULTURA DO ARROZ IRRIGADO, 24., Porto Alegre, 2001. Anais... Porto Alegre: IRGA, 2001. p. 664-666.

5 BARBOSA, F.F.; FAGUNDES, C.A.A.; OLIVEIRA, C.F.; ELIAS, M.C. Umidade relativa do ar na secagem estacionária e efeitos na operação e na qualidade de grãos de arroz. CONGRESSO BRASILEIRO DE CIÊNCIA E TECNOLOGIA DE ALIMENTOS, 18., 2002, Porto Alegre. Anais... Porto Alegre: CBCTA, 2002. CD-ROM. 
6 BATTACHARYA, K.R.; ALI, S.Z. Changes in rice during parboiling, and properties of parboiled rice. In: POMERANZ, Y. Advances in cereal science and technology. Saint Paul: AACC, 1985. v. 7, p. 105-67.

7 BRASIL. Ministério da Agricultura, do Abastecimento e da Reforma Agrária. Secretaria Nacional de Defesa Agropecuária. Regras para análise de sementes. Brasília DF, 1992. 365 p.

8 BRASIL. Ministério da Agricultura e Reforma Agrária. Comissão Técnica de Normas e Padrões. Normas de identidade, qualidade, embalagem e apresentação do arroz. Brasília, v.8, n.20/6, 25 p. 1988. Disponível em: <http://extranet.agricultura.gov.br/sislegis-consulta/servlet/VisualizarAnexo?id=7106>. Acesso em: 30 nov. 2009.

9 CONAB. Companhia Nacional de Abastecimento. Indicadores de agropecuária, estimativa de safras. Disponível em: <http://www.conab.gov.br>. Acesso em: 30 nov. 2009.

10 CONRAD, V.J.D.; MARINI, L.J.; WALLY, A.P.S.; HAAS, L.I.R.; RUPULLO, G.; FAGUNDES, C.A.A.; ELIAS, M.C. GLP no ar da secagem estacionária e processo de beneficiamento nas propriedades de consumo de arroz. In: CONGRESSO BRASILEIRO DO ARROZ IRRIGADO, 3., REUNIÃO DA CULTURA DO ARROZ IRRIGADO, 25., Porto Alegre, 2003. Anais... Porto Alegre: IRGA, 2003. p. 605-607.

11 ELIAS, M.C. Pós-colheita e industrialização de arroz. In: GOMES, A.S.G.; MAGALHÃES Jr., A.M. Arroz irrigado no Sul do Brasil. Brasília: Embrapa Clima Temperado, 2004. p.983-1053.

12 ELIAS, M.C. Tecnologias para armazenamento e conservação de grãos em médias e pequenas escalas. Pelotas: UFPEL/COREDE-SUL, 2002. 218 p.

13 ELIAS, M.C. Tempo de espera para secagem e qualidade de arroz para semente e indústria. Pelotas, 1998. 132 p. Tese (Doutorado em Ciência e Tecnologia de Sementes) - Faculdade de Agronomia "Eliseu Maciel", UFPEL, 1998.

14 ELIAS, M.C.; FAGUNDES, C.A.A.; DIAS, A.R.G. Aspectos fundamentais e operacionais na qualidade de grãos de arroz. Lavoura Arrozeira, Porto Alegre, v. 52, n. 435, p. 56-60, 2004.

15 ELIAS, M.C.; ROMBALDI, C.V.; SILVA, J.A.; NORA, L.; DIAS, A.R.G; SCHIRMER, M.A. Industrialização de arroz. Polo de Alimentos. Pelotas: UFPEL/COREDESUL, 2003. $38 \mathrm{p}$.

16 FAN, F.; SIEBENMORGEN, T. J.; YANG, W. A study of head rice yield reduction of long- and medium-grain rice varieties in relation to various harvest and drying conditions. American Society of Agricultural Engineers, v. 43, n. 6, p. 1709-1714, 2000.

17 GUTKOSKI, L.C. Efeitos das condições de maceração e de autoclavagem na qualidade industrial e comercial dos grãos de arroz (Oryza sativa, L.) parboilizados. Pelotas, 1991. 122 p. Dissertação (Mestrado em Ciência e Tecnologia Agroindustrial) - Faculdade de Agronomia "Eliseu Maciel", Universidade Federal de Pelotas.

18 GUTKOSKI, L.C.; ELIAS, M.C. Estudos comparativos das operações unitárias de parboilização de arroz, realizadas em escala industrial e laboratorial. Lavoura Arrozeira, Porto Alegre, v. 45, n. 404, p. 3-8, 1992.

19 IRGA. Instituto Rio Grandense do Arroz. Deputado destaca produção de arroz no Estado. Disponível em: <http:/ /www.irga.rs.gov.br>. Acesso em: 30 nov. 2009.

20 LORINI, I.; MIIKE, L. H.; SCUSSEL, M. V. Armazenamento de grãos. Campinas: IBG, 2002. 1000 p.

21 PEREIRA, F.M.; BOEMEKE, L.R.S.; OLIVEIRA, M.; SOFIATTI, V.; FAGUNDES, M.A.; SCHIRMER, M.A.; ELIAS, M.C. Temperatura e demanda energética na secagem estacionária de arroz. In: SIMPÓSIO SUL BRASILEIRO SOBRE QUALIDADE DE ARROZ, 1., Pelotas, 2003. Anais... Passo Fundo: ABRAPÓS, 2003. p. 445-50.

22 SAEG. Sistema para análises estatísticas. Versão 9.1. Viçosa: Fundação Arthur Bernardes, 2007.

23 SANTOS, E. O arroz em destaque na AL. Disponível em: <http://www.al.rs.gov.br>. Acesso em: 10 jul. 2006.

24 SOSBAI. Sociedade Sul Brasileira de Arroz Irrigado. Arroz irrigado: recomendações técnicas da pesquisa para o sul do Brasil. Camboriú: Epagri, 2003. 124 p.

TAVARES, M.A. O mercado do arroz em 2004. Lavoura Arrozeira, v. 52, n. 435, p. 42-3, 2004.

\section{AGRADECIMENTOS}

Ao Instituto Rio Grandense do Arroz pelo material experimental e uso das instalações durante parte do experimento. À CAPES, ao CNPq e à FAPERGS pela concessão de bolsas de estudos e auxílio financeiro. À Secretaria de Ciência e Tecnologia do Rio Grande do Sul - Programa Polos de Inovação Tecnológica, ao Polo de Alimentos e ao COREDE-SUL pelo auxílio financeiro, pelo material e pelo uso das instalações. As empresas DRYERATION e ULTRAGAZ pelo valioso auxílio na execução das pesquisas. 